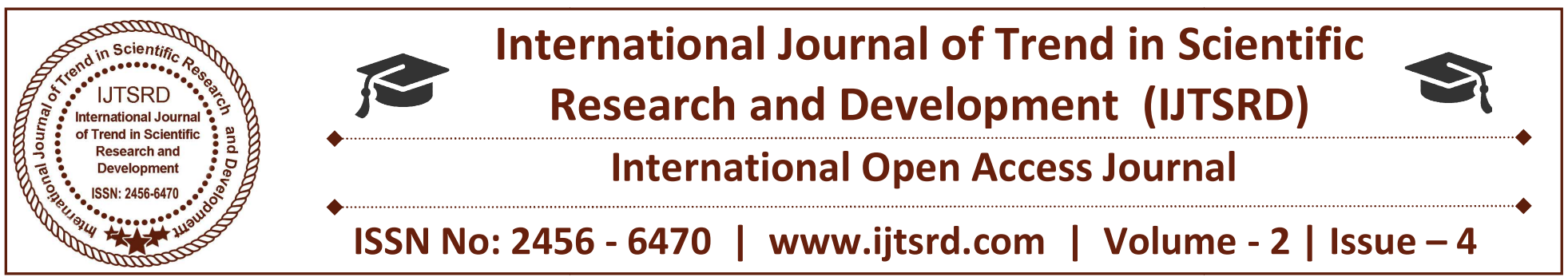

\title{
Power Conversion Interface
}

\author{
Matthew N. O. Sadiku, Adedamola Omotoso, Sarhan M. Musa, Adebowale E. Shadare \\ Roy G. Perry College of Engineering, Prairie View A \& M University, \\ Prairie View, Texas, United State
}

\begin{abstract}
The global environment is degrading and all efforts are being made to reverse the situation. Power generation based on fossil fuel is partly responsible for the polluting emissions. Because of this, renewable (non-pollutant) energy sources have received a lot of attention in the power community. The cost of renewable energies is expected to fall as the demand increases. Power conversion interfaces (PEI) are needed to integrate renewable energy sources with the existing electrical power system. This paper provides a brief introduction on power conversion interfaces.
\end{abstract}

Keywords: power conversion interface, $A C-D C$ power converter, $D C$-DC power converter

\section{INTRODUCTION}

Similarly, the output of wind generator cannot be connected directly to the utility because variable amplitude and frequency and wind speed. The variable frequency $\mathrm{AC}$ output needs to be converted to $60 \mathrm{~Hz}$ AC for utility connection. The power converter interfaces (PCIs) are necessary to operate well in certain fault conditions $[1,2]$.

Systems that merge both wind and solar sources are more effective and are referred to as "hybrid systems." They can be stand-alone systems or gridconnected systems. The voltage source converters (VSC) are the power interfaces between AC grids and DC grids in the hybrid power system. A typical hybrid power system is shown in Figure 1 [3].

\section{TYPES OF POWER CONVERSION}

The traditional sources of energy are fossil fuels, hydro, and nuclear. Renewable energy sources (such as solar, hydro, geothermal, and wind energy) are becoming important due to the limited reserves of fossil fuels, their negative impact on environment, and greenhouse emissions. The production of clean, green energy is preferred as the demand of electric power increases.

Power converters play an important role in power generation, transmission, and distribution. An AC-DC or DC-DC power interface is always needed between renewable energy source (RES) such as wind and solar energy and power system. For example, the output of the solar cell array is DC (direct current) power and it cannot be connected directly to the utility. The DC power needs to be converted to AC for utility connection.

The power converter could be for AC-DC or DC-DC. For AC-DC converter, the DC power of the diode rectifier can supply $\mathrm{DC}$ loads or be further converted into fixed-frequency $\mathrm{AC}$ power by an inverter for $\mathrm{AC}$ loads. The electric power is defined as the product of the voltage and current and this product must be controlled to obtain the maximum possible power at all times. High power factor is desirable in order to convey real power from the AC grid to a DC load. The charging power of a battery is converted from the utility through an AC-DC power conversion interface. A typical power conversion interface is shown in Figure 2 [4]. Typical AC-DC converters for single phase and three phases are illustrated in Figure 3 [5].

The DC-DC converter regulates the load voltage from the series/parallel capacitor set and improves the power conversion efficiency of the system. It controls the charge and discharge of the storage systems (such 
as batteries). It may be regarded as a boost converter since it can be employed to boost a lower DC voltage source. It adjusts the voltage and frequency to the load. Several DC-DC stages can be used to control different energy sources. Different DC-DC converter topologies are displayed in Figure 4 [6].

Generally, the DC output voltage of the renewable source needs boosting to a higher value by using DC$\mathrm{DC}$ converters. Then the DC-AC inverters are used in converting the voltage to the utility compatible $60 \mathrm{~Hz}$ AC. The convention cascade topology is a DC-DC forward converter with a DC-AC inverter. A few applications exist for cascaded DC-AC and AC-AC.

\section{BENEFITS AND CHALLENGES}

Multiple input converters can be classified into three groups: magnetic, electrical, and electromagnetic. The main motive for using converters is using less semiconductors, occupying less volume, and reducing the cost of manufacturing [7].

Small power plants can be combined to produce a large amount of energy. In this case, there is no need for building transmission power lines since the energy production is distributed. However, the renewable energy power plants must comply with legislation.

An AC-DC rectifier consisting of a diode and a capacitor is cheap but has a seriously distorted input current and a poor power factor.

\section{CONCLUSION}

Renewable energy sources are expected to have a significant impact on the energy market in future. These sources include solar, hydro, geothermal, and wind energies. To convert the harvested power into useful power that can be connected directly with the utility grid requires electronic capabilities, such as power conversion interfaces and power electronic interfaces. Power converters are used in various applications such as hybrid energy systems, electric vehicles, aerospace, and portable electronic devices [8]. More information on power converters can be found in [9].

\section{REFERENCES}

1. M. Zhu et al., "Protected control method for power conversion interface under unbalanced operating conditions in $\mathrm{AC} / \mathrm{DC}$ hybrid distributed grid," IEEE Transactions on Energy Conversion, vol. 31, no. 1, March 2016, pp. 57-68.

2. J. C. Wu, M. J. Ho, and H. L. Jou, "New five-level inverter-based grid-connected power conversion interface," IET Power Electron, vol. 6, no. 7, 2013, pp. 1239-1247.

3. P. Ferreira et al., "Interfaces for renewable energy sources with electric power systems," Situation and Perspectives for the European Union, Porto, Portugal, May 2003.

4. J. C. Wu, H. L. Jou, and J. Y. J. Jian, "Singlephase multi-level AC-DC power conversion interface," IET Power Electron, vol. 9, no. 3, 2016, pp. 449-456.

5. V. P. Pires et al., "Power converter interfaces for electrochemical energy storage systems - A review," Energy Conversion and Management, vol 86, 2014, pp. 453-475.

6. S. Sivakumar et al., "An assessment on performance of DC-DC converters for renewable energy applications," Renewable and Sustainable Energy Reviews, vol. 58, 2016, pp. 1475-1485.

7. S. Khosrogorji et al., "Multi-input DC/DC converters in connection with distributed generation units - A review," Renewable and Sustainable Energy Reviews, vol. 66, 2016, pp. 360-379.

8. Z. Rehman, I. Al-Bahadly, and S. Mukhopadhyay, "Multiinput DC-DC converters in renewable energy applications - An overview," Renewable and Sustainable Energy Reviews, vol. 41, 2015, pp. 521-539.

9. P. J. Grbovic, Ultra-capacitors in Power Conversion Systems: Applications, Analysis and Design from Theory to Practice. Chichester, UK: John Wiley \& Sons, 2014.

\section{About the authors}

Matthew N.O. Sadiku (sadiku@iee.org) is a professor at Prairie View A\&M University, Texas. He is the author of several books and papers. He is an IEEE fellow. His research interests include computational electromagnetic and computer networks.

Adedamola A. Omotoso (aaomotoso@yahoo.com) is a masters student at Prairie View A\&M University, Texas. His areas of interest are power and control 
system. He is currently working on a research in electromagnetic compatibility in smart grids.

Sarhan M. Musa (smmusa@pvamu.edu) is a professor in the Department of Engineering Technology at Prairie View A\&M University, Texas. He has been the director of Prairie View Networking Academy,
Texas, since 2004. He is an LTD Sprint and Boeing Welliver Fellow.

Adebowale Shadare (shadareadebowale@yahoo.com) is a doctoral student at Prairie View A\&M University, Texas. He is the author of several papers.
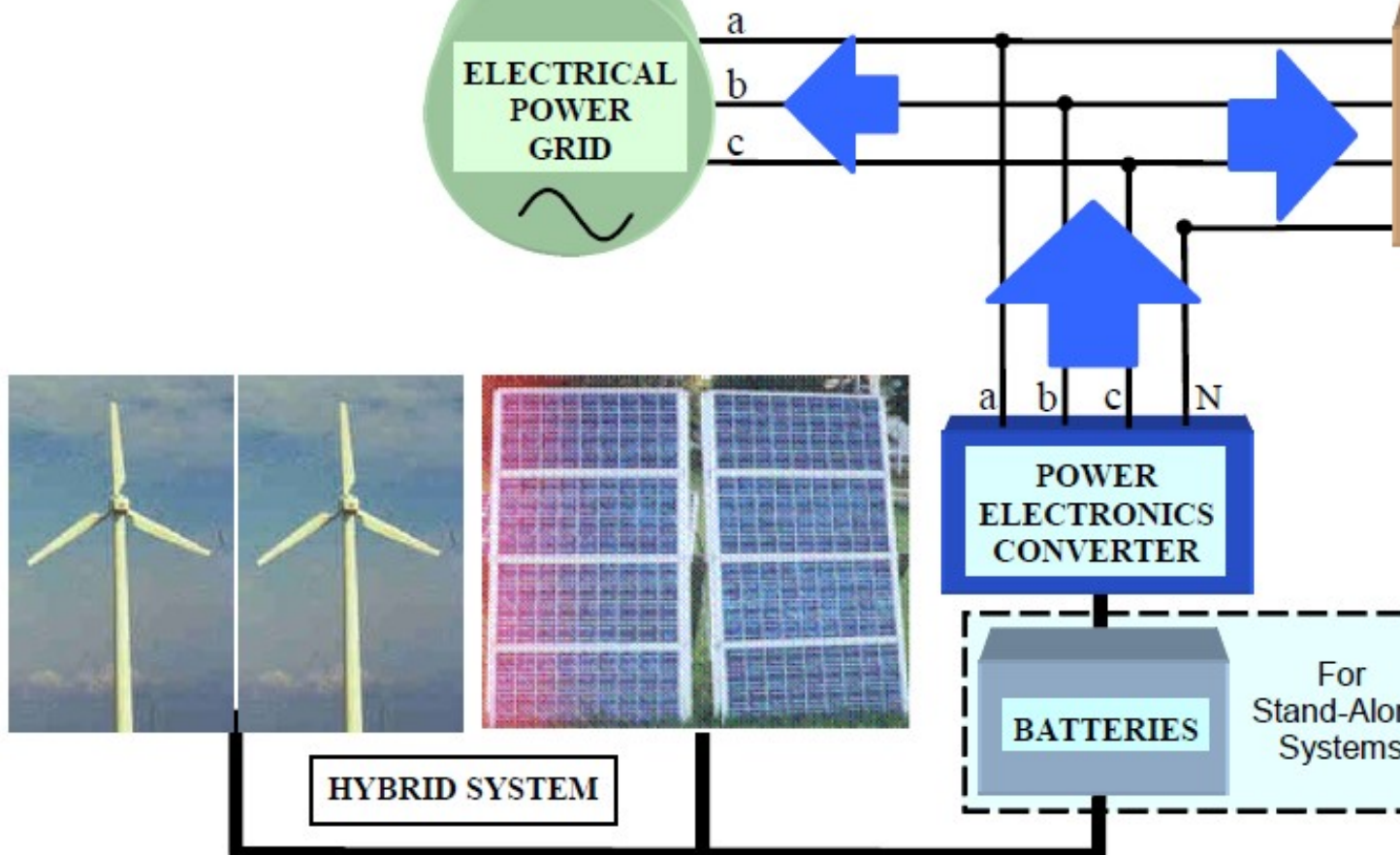

LOADS

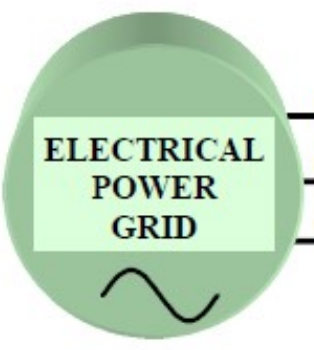


Figure 2 A typical power conversion interface [4].

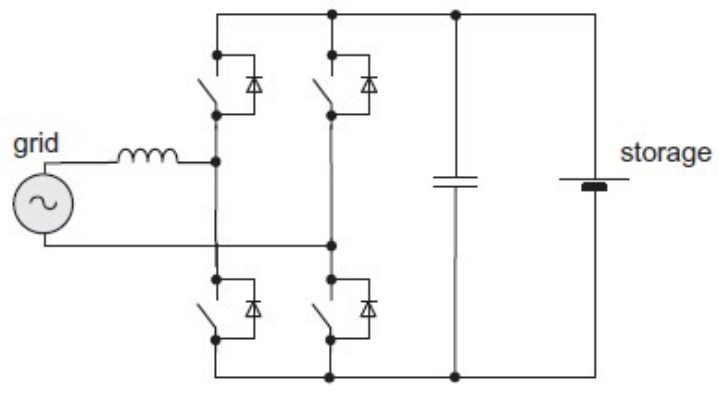

(a)

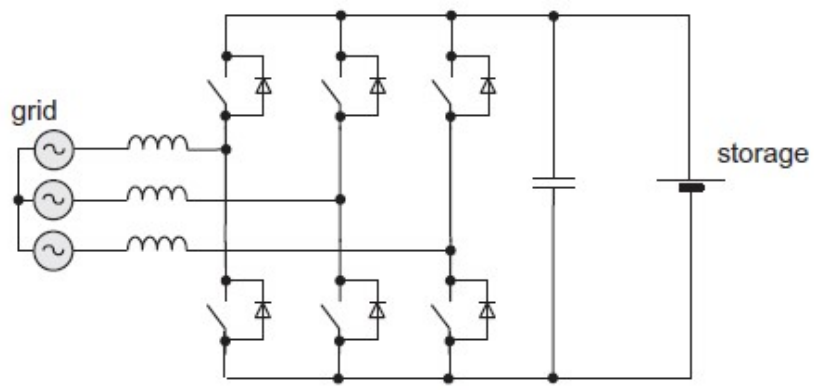

(b)

Figure 3 Typical AC-DC converters for: (a) single-phase, (b) three-phase [5].

a

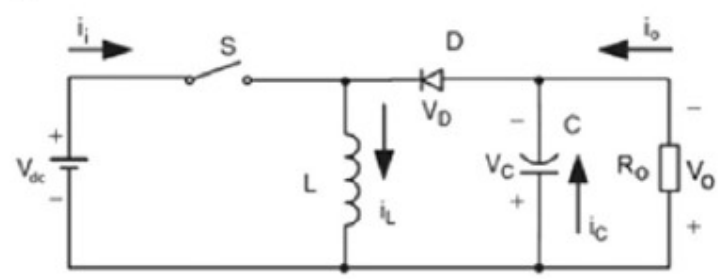

C

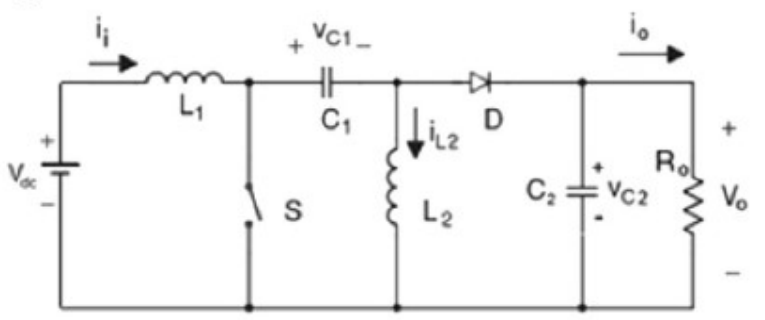

b

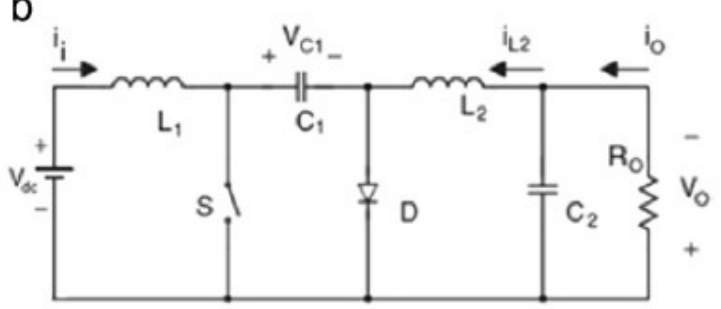

d

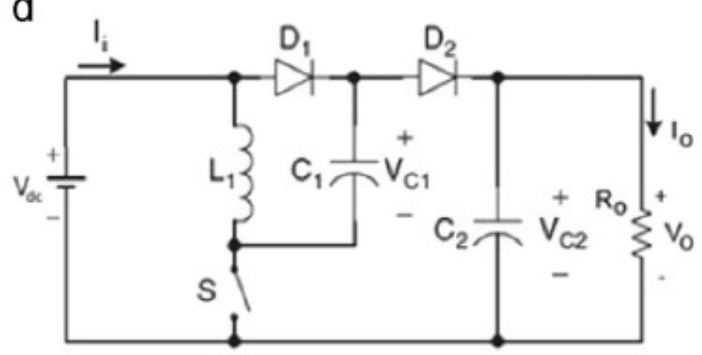

Figure 4 Different DC-DC converter topologies [6]. 